\title{
Reflexões sobre os (não) usos das tecnologias digitais na educação física escolar ${ }^{1}$
}

\section{Reflections on the (non) uses of digital technologies in school physical education}

\section{Reflexiones sobre los (no) usos de las tecnologías digitales en la educación física escolar}

\author{
iD Fábio Souza de Oliveira \\ Secretaria de educação do estado da Bahia, Feira de Santana, Bahia, Brasil \\ E-mail: fabiopatchanka@hotmail.com \\ (iD) Claudio márcio oliveira \\ Universidade Federal de Minas Gerais, Belo Horizonte, Minas Gerais, Brasil \\ E-mail: clamoliv1974@hotmail.com
}

\begin{abstract}
Resumo: O objetivo deste ensaio teórico consistiu em evidenciar um conjunto de argumentações que subsidiassem as reflexões sobre os (não) usos das tecnologias digitais na Educação Física escolar. Inspiramonos fundamentalmente no campo da Mídia-Educação e em pensadores da Escola de Frankfurt, que balizaram os olhares sobre as tecnologias na escola e na Educação Física. É possível vislumbrar a Mídia-Educação como abordagem privilegiada para o trato com o conteúdo midiático relacionado à cultura corporal. Finalmente, ressalta-se o papel necessário e urgente da Educação Física escolar em criar espaços de reflexão sobre os conteúdos midiáticos, tornando os estudantes conscientes das concepções distorcidas ou empobrecidas sobre a cultura corporal.
\end{abstract}

Palavras-chave: Educação Física. Mídia-educação. Tecnologias Digitais.

\begin{abstract}
The objective of this theoretical essay was to highlight a set of arguments that cold support the reflections on the (non) uses of digital technologies in school Physical Education. We were mainly inspired
\end{abstract}

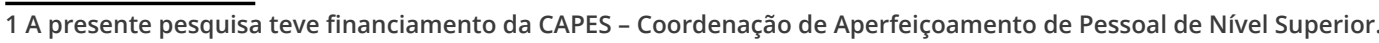


by the field of Media-Education and thinkers of the Frankfurt School, which marked out the views on the technologies in the school and in Physical Education. It is possible to see Media-Education as a privileged approach for dealing with media content related to body culture. Finally, it emphasizes the necessary and urgent role of school Physical Education in creating spaces for reflection on media content, making students aware of distorted or impoverished conceptions about body culture.

Keywords: Physical Education. Media-Education. Digital Technologies.

Resumen: El objetivo de este ensayo teórico fue destacar un conjunto de argumentos que apoyan las reflexiones sobre los usos (no) de las tecnologías digitales en la educación física escolar. Nos inspiramos principalmente en el campo de la Educación en Medios y los pensadores de la Escuela de Frankfurt, que marcó las opiniones sobre las tecnologías en la escuela y en la Educación Física. Es posible ver la Educación en Medios como un enfoque privilegiado para tratar con contenido mediático relacionado con la cultura corporal. Finalmente, enfatizamos el papel necesario y urgente de la Educación Física escolar en la creación de espacios para la reflexión sobre el contenido de los medios, haciendo que los estudiantes tomen conciencia de los conceptos distorsionados o empobrecidos sobre la cultura corporal.

Palabras clave: Educación Física. Media-Educación. Tecnologías digitales. 
Reflexões sobre os (não) usos das tecnologias digitais na educação física escolar Fábio Souza de Oliveira • Claudio márcio oliveira

\section{Introdução}

Consideramos que a inserção das tecnologias digitais de informação e comunicação (TDIC) no contexto escolar é um dos movimentos que têm merecido maior atenção na sociedade contemporânea, seja pela dinâmica da produção e acesso ao conhecimento, seja como instrumento que potencializa o ensino e a aprendizagem por sua característica multimidiática, ou, ainda, por permitir o registro e compartilhamento das ações docentes/ discentes. No ambiente escolar, esse fenômeno tem se verificado crescente e complexo com a criação e chegada de novos dispositivos. De modo particular, o telefone celular do tipo smartphone tem se tornado, para além de uma tecnologia de comunicação, um dispositivo multifuncional de posse da quase totalidade dos alunos. Esse equipamento, no entanto, não tem sido utilizado do ponto de vista educacional e tem se tornado um entrave sob diversos aspectos no ambiente escolar, concorrendo com as propostas formativas em sala de aula ao dispersar a atenção dos alunos com seus conteúdos.

Este artigo de revisão tem por objetivo refletir sobre o lugar e o não-lugar das Tecnologias Digitais de Informação e Comunicação (TDIC's) na Educação Física Escolar. Para tanto, traz como um dos personagens centrais dessa trama a figura do smartphone no interior das dinâmicas da cultura escolar. Para realizar tal empreitada, uma pluralidade de abordagens teóricas é posta em diálogo, da Teoria Crítica à Mídia-Educação, da Didática à Educação Física Escolar, rejeitando posicionamentos maniqueístas, relativismos ou posições de otimismo ingênuo em torno da problemática em questão.

Nos termos de C.Wright Mills (1972), o que é proposto é um Artesanato Intelectual, que consiste justamente no movimento de transformação de um problema social em um problema de investigação sociológica, pois captura uma inquietante questão escolar de nossos tempos - a presença (in)desejada dos smartphones nas 
Reflexões sobre os (não) usos das tecnologias digitais na educação física escolar Fábio Souza de Oliveira • Claudio márcio oliveira

escolas - para constituir-se em um problema de investigação/intervenção pedagógica na Educação Física Escolar.

\section{O(não)lugardastecnologiasde informaçãoecomunicação}

A respeito das tecnologias digitais móveis, sobretudo do uso de smartphones e tablets, ainda não há consenso sobre seu emprego educacional. Se por um lado há projetos e investimentos para inserção de computadores e tablets nas escolas públicas, na contramão, é possível verificar uma série de legislações que regulam ou proíbem o uso do celular nessas mesmas escolas. Nossa proposição acerca dessa temática, neste estudo, pretende extrapolar os muros do simples "sim" ou "não", buscando novas aproximações sobre o seu lugar na educação e, de modo particular, na Educação Física.

Para Belloni (2009), se é fundamental reconhecer a importância dessas tecnologias e a urgência de se criar mecanismos para sua integração à educação, é também necessário evitar o deslumbramento que leva ao uso irrefletido da tecnologia por si, menos por suas virtudes pedagógicas do que por suas características técnicas. Assim, avolumam-se salas de informática com computadores, filmadoras e máquinas fotográficas, além de outros equipamentos que compõem o repertório tecnológico da escola, sem, entretanto, estabelecer em seus planejamentos os meios pelos quais essas mesmas tecnologias não restem limitadas à mera ilustração das aulas.

A esse respeito, Martín-Barbero (2014, p. 12) ressalta que "Localizada no exterior do modelo pedagógico e comunicativo, a tecnologia só pode contribuir para modernizar a "decoração" do ensino, e não para a transformação radical das estruturas ou metodologias, tampouco para as práticas de aprendizagem". Na verdade, é mais provável que elas reforcem modelos de exclusão, gerem custos adicionais, ocupem espaços que poderiam ser pro- 
Reflexões sobre os (não) usos das tecnologias digitais na educação física escolar Fábio Souza de Oliveira • Claudio márcio oliveira

dutivos do ponto de vista educacional ou, inclusive, contribuam para a manutenção dos discursos midiáticos.

Desse modo, não há lugar para a adesão indiscriminada das tecnologias, simplesmente por estarem disponíveis e permearem as vidas dos estudantes de todo o país. Não será possível adotá-las pelos argumentos superficiais das telas coloridas e dos conteúdos audiovisuais, que poderão prender a atenção de educandos nas salas de aulas, ou, ainda, por serem supostamente os livros uma tecnologia em franca decadência. A fala de Silva (2014, p. 19) exemplifica bem a postura acima quando ele diz:

A chamada "geração audiovisual" está em outra e a escola, se quiser atingir esse público, se quiser fazer com que ele se interesse pelos seus conteúdos "ultrapassados", "enfadonhos", sem cor, forma e cheiro, "livresco", entre outras características "pré-históricas" que compõem a escola nos dias de hoje, precisa se adequar a esse novo tempo. A saída? A utilização das tecnologias da informação e comunicação (TICS) na organização dos conteúdos escolares, pois assim, e só assim, os alunos se sentirão motivados para irem à escola e esta estará sintonizada com o novo tempo [...].

O posicionamento "salvacionista", como no trecho acima, que credita, em nome das tecnologias, a impossível missão de devolver à escola o protagonismo na aquisição do conhecimento, é falacioso e equivocado, tomando o lugar da real possibilidade de uso desses dispositivos. Sobre isso, Martín-Barbero (2014) identifica que, de alguma forma, a escola tem procurado introduzir e fazer uso dos meios digitais, mas se trata unicamente de um uso modernizador e instrumental, mudando a fachada da escola, sem, de fato, alterá-la (a escola). Para ele, o que há, neste caso, é uma instrumentalização das tecnologias que, notadamente, menos alteram as relações da escola com a sociedade do que encobrem a profundidade da crise escolar. 
Reflexões sobre os (não) usos das tecnologias digitais na educação física escolar Fábio Souza de Oliveira • Claudio márcio oliveira

Para Adorno (1995), há na relação atual com a técnica algo de exagerado, irracional e patogênico, uma inclinação a considerá-la como um fim em si mesma. Na contramão de uma postura reificada a respeito das tecnologias digitais, também não deverá haver espaço para a sua demonização. A manutenção dos argumentos contrários ao uso das tecnologias nas escolas não pode sustentar-se em afirmações sobre alunos que não prestam mais atenção às aulas ou que depois do advento dos celulares e tablets não há mais espaço para as leituras ou, ainda, que o problema da educação é o celular smartphone. Martín-Barbero (2014) acredita que parte significativa do mundo adulto, de modo particular o acadêmico, atribui aos meios audiovisuais a causa da crise da leitura e do empobrecimento cultural, acreditando poder encontrar nos livros a salvação para o que ele chama de "nova barbárie midiática". Infelizmente, essa polarização é tão comum que já recebeu denominação pelos teóricos que a estudam. São "apocalípticos" os pessimistas, denunciadores da banalização das produções humanas pela chamada "indústria cultural" (ADORNO, 2002), e são chamados de "integrados" os tidos como otimistas ingênuos que veem nos meios técnicos apenas um canal para a democratização do acesso às produções culturais (PIRES, 2002). Esse mesmo autor destaca como principal equívoco nesses posicionamentos a busca por um sim ou um não, pelo que é bom ou ruim, enquanto para ele haverá que se identificar qual ação é possível, a fim de permitir que as tecnologias digitais possam veicular valores culturais.

Fantin e Rivoltella (2012) apaziguam a questão quando dizem que a cultura midiática não está e nunca estará em oposição ao que se ancora no impresso e no oral do espaço presencial, pois um precisa do outro, do mesmo modo que vão coexistir a cidade virtual e a presencial. Além disso, não há uma boa ou má tecnologia (McLUHAN, 1964). Tampouco há uma tecnologia neutra. Tratase sim dos seus usos, da apropriação feita pelo homem para cada tecnologia, das decisões sobre o que se fazer com elas.

Quando nos referimos ao saber escolarizado, outra análise que deve ser interposta é que as tecnologias digitais trazem uma série 
Reflexões sobre os (não) usos das tecnologias digitais na educação física escolar Fábio Souza de Oliveira • Claudio márcio oliveira

de outros desdobramentos que não somente os aumentos qualitativos e quantitativos de produção e transmissão de informações. $\mathrm{Na}$ era digital, os (hiper) textos são povoados por links, documentos interligados que constituem acessos a outros textos (KENSKI, 2012), abrindo possibilidade para incontáveis combinações de caminhos no percurso de construção do conhecimento, ficando o aprendente livre para seguir por onde sua curiosidade, atenção, sensibilidade ou realidade Ihe indicar, aprofundando as informações sobre o assunto até quando se achar que já é suficiente.

A possibilidade de escolher os percursos de aprendizagem permite certo grau de independência e autoria por parte dos alunos no que se refere ao aprender. Enquanto um aluno pode optar em acessar um link, aprofundando um determinado termo, ou acessando outros links daquela via de aprendizagem, outros podem optar por não os acessar, escolhendo diferentes possibilidades. Paradoxalmente, esse "benefício" da autoria e da independência também pode ser compreendido como imenso potencial de distração. Sobre isso, Türcke (2010, p.70) afirma que

\begin{abstract}
O olho do leitor encontra constantemente conceitos marcados chamando para outros textos que prometem uma leitura mais excitante do que a que se faz agora, e apenas o esforço de uma negação teimosa contra tais saltos de página permite que se esteja em condições de ler o texto em questão, de uma só vez, até o fim. Cria-se aqui um imenso potencial de distração.
\end{abstract}

Podemos afirmar que, em tempos de tecnologias digitais, os estímulos audiovisuais que afetam crianças e adolescentes em idade escolar são crescentes e, desse modo, não podemos nos furtar ainda aos mecanismos de percepção e atenção, estando atentos à possível saturação desses processos. Türcke (2010) já previa o papel dos meios audiovisuais atualmente, que pudessem atingir os canais sensoriais ultrassaturados dos indivíduos como uma injeção multissensorial. Pucci et al. (2016, p. 20), ao tratarem desse assunto, dizem que "cada corte de imagem atua como golpe 
Reflexões sobre os (não) usos das tecnologias digitais na educação física escolar Fábio Souza de Oliveira • Claudio márcio oliveira

óptico que irradia para o espectador um "alto lá", "preste atenção", "olhe para cá" e aplica uma pequena nova injeção de atenção, uma descarga mínima de adrenalina [...]". Diante de tantos estímulos, o que toca, o que atinge cada indivíduo, ou melhor, o que chama a atenção é aquilo que for "agudizante" o suficiente para o sistema nervoso, ainda que por um pequeno instante. Em outras palavras, os estímulos do ambiente do dia a dia, assim como aqueles do meio escolar formal, parecem não ser páreo para aqueles apresentados pelas mídias digitais. Os primeiros "representam estímulos de menos para serem percebidos" (TÜRCKE, 2010, p.66).

Nesse contexto de tecnologias digitais, onde todos são afetados constantemente com uma infinidade de estímulos, Sacristán e Pérez Gomes (1998) também ressaltam como esse ambiente pode transformar-se em obstáculo para o desenvolvimento ou, no mínimo, não permitir a formação de esquemas operativos de conhecimento. Em outras palavras, o ambiente tecnológico pode isto, mas também aquilo, cabendo aos atores da educação estabelecerem a ecologia desejada no sentido de obter das tecnologias a resposta para a mobilização de estudantes e, por que não dizer, de professores.

Portanto, é necessário refletir sobre quais os princípios que orientam a entrada das tecnologias digitais nas propostas escolares, sob pena de estarmos reforçando relações equivocadas com o saber, ampliando conhecimentos sem, contudo, proporcionarmos a ecologia necessária para a edificação de saberes. Além disso, Charlot (2013) nos diz que a escola brasileira tem reforçado uma relação instrumental com o saber, ficando subsumida a atividade intelectual, do saber pelo prazer de saber. Ao adotar as tecnologias como estratégia de ensino e aprendizagem, os sistemas de ensino e as unidades escolares devem estar atentos aos princípios éticos, políticos, sociais e econômicos que as sustentam a fim de evitar o que Charlot (2013, p. 59) já identificava: "há cada vez mais alunos que vão à escola apenas para "passar de ano", sem encontrar nela sentido nem prazer". Por outro lado, cumpre dizer que, nem sempre (senão na maior parte do tempo), prazer e sentido estarão de mãos dadas na proposta escolar. 
Reflexões sobre os (não) usos das tecnologias digitais na educação física escolar Fábio Souza de Oliveira • Claudio márcio oliveira

Refutar o ideário maniqueísta que trata as tecnologias como "isto ou aquilo" é reconhecer seu potencial que entrelaça sentidos e direções, e que, por isso mesmo, pode concebê-la como importante aliada na reconfiguração da escola atual.

\section{Mídia-Educação: limites, possibilidades e tensões acerca da apropriação crítica das mídias "na" e "pela" escola}

Durante muito tempo, a televisão preocupou estudiosos das mídias por sua influência nas representações que os estudantes constroem da realidade. De custo relativamente baixo, as Tv's entraram nos lares e ocuparam parte significativa do tempo da população com seus programas e propagandas, propondo um "sem fim" de possibilidades de aquisição, ou, no dizer de Adorno, impulsionando a "indústria cultural" (ADORNO, 2002), apresentando conceitos e verdades que essa mesma população não estava pronta para questionar. Mais recentemente, com o advento das tecnologias digitais, e todas as transformações por elas postas à sociedade nesse novo momento tecnológico, percebe-se um certo deslocamento desse poderio da televisão para outras mídias, sobretudo para o computador, o tablet e o celular (FANTIN, 2012).

Além dessas aprendizagens que são impostas por impregnação (BELLONI, 2009), essas tecnologias têm em comum o potencial de atender à aparente necessidade de se ter a atenção sempre saturada, por realização de várias tarefas ao mesmo tempo, a ampliação do perfil de usuário exclusivamente espectador para consumidor e produtor, a necessidade de estar sempre conectado, que, de algum modo, assemelha-se a busca por saturação, fuga dos silêncios. Outros tantos entraves podem ser elencados a respeito das mais recentes tecnologias, que é difícil conceber quais os que mais desafiam a escola. Violência virtual, cópia de atividades escolares que tomam o lugar do fazer e do refletir, desvio do tempo escolar para a diversão com outras motivações através das telinhas coloridas dos tablets, notebooks, celulares, difusão das fake 
Reflexões sobre os (não) usos das tecnologias digitais na educação física escolar Fábio Souza de Oliveira • Claudio márcio oliveira

News, os casos de cyberbullismo, a violação de dados dos perfis de usuários, sem mencionar as possíveis reverberações das relações virtuais no campo afetivo (AMENDOLA, GIGLI, MONTI, 2018).

A aprendizagem por impregnação é um dos pontos importantes a respeito da presença das tecnologias em meio a estudantes, para Belloni (2009). Esse modelo de aprendizagem é, segundo a autora, poderoso e eficaz, sobretudo para os mais novos, visto seu poder de influenciar a aprendizagem inconsciente, involuntária, questão que se agrava quando consideramos o quantitativo de horas de exposição frente às telinhas. Essa mesma autora ressalta a transferência da violência virtual para o campo real, uma vez que as imagens audiovisuais, da TV e outros dispositivos digitais tendem a naturalizar e legitimar o uso da violência como meio de resolução de conflitos.

Por outro lado, as tecnologias digitais oferecem um "sem fim" de possibilidades construtivas do ponto de vista da formação escolar que, certamente, adotadas de forma integrada à proposta educacional, alinhadas aos projetos escolares, sustentadas por princípios políticos, éticos e estéticos, deverão contribuir para a edificação de uma nova realidade escolar, partindo de novas formas de conceber a educação, próprias de um tempo digital.

Nesse cenário, estando o campo da tecnologia educacional limitado frente às demandas impostas pelas tecnologias digitais, a Mídia-Educação surge como campo que se dedica à compreensão desse novo tempo escolar e busca respostas a estas e outras demandas, próprias da cultura midiática (BELLONI, 2009). Para Fantin (2006), a Mídia-Educação é uma importante chave para decifrar a cultura moderna. Para ela, somos a cada instante educados pelas mídias, por sons e imagens, e a escola está longe de problematizar suficientemente as repercussões das mídias nas mudanças culturais.

As pesquisas no campo da Mídia-Educação têm voltado seus olhares para os diversos canais midiáticos como o rádio, revistas, jornais, televisão e, de modo particular, àquelas que, atualmente, mais têm influenciado o fazer escolar: as tecnologias digitais, 
Reflexões sobre os (não) usos das tecnologias digitais na educação física escolar Fábio Souza de Oliveira • Claudio márcio oliveira

incluindo a internet (SOUSA, BORGES, 2018). Através dos canais midiáticos, as informações têm chegado aos estudantes em velocidades e volumes impossíveis de serem refletidos, sustentando concepções de verdade fragmentadas, distorcidas ou ideologicamente arquitetadas, antes mesmo de serem propostas didaticamente pela escola. Para Sousa e Borges (2018), a Mídia-Educação busca superar a construção instrumental do conhecimento enquanto via unidimensional, tão comum no cenário educacional brasileiro, englobando estudos sobre a produção com as mídias e as reflexões a respeito dos diversos conteúdos midiáticos. É justamente aqui que a Mídia-Educação avança com relação ao campo das tecnologias educacionais, por propor o uso e apropriação das diversas tecnologias, sem perder de vista o desvelar das ideologias, pré-conceitos, violências e outras imposições trazidas como pano de fundo nos discursos midiáticos.

O termo Mídia-Educação surge da interface entre educação e comunicação, dois campos em igualdade de espaços e sem hierarquizar um termo em detrimento do outro, denotando suas contribuições equânimes (MEZZAROBA; GARCIA; DORENSKI, 2013; FANTIN, 2006). Para Fantin (2012), a Mídia-Educação é "entendida como a possibilidade de educar para/sobre as mídias, com as mídias e através das mídias, a partir de uma abordagem crítica, instrumental e expressivo-produtiva". Para a autora, educar para as mídias é tornar os estudantes capazes de compreender, interpretar e avaliar os conteúdos das diversas mídias. Educar com as mídias inscreve-se no âmbito da didática, valendo-se das tecnologias digitais como recurso didático, inserindo novas possibilidades de educar com esses recursos, numa perspectiva instrumental. Educar através das mídias significa utilizar as mídias como linguagem, como forma de expressão e produção.

Além disso, Fantin (2012) destaca a Mídia-Educação como campo central na formação de estudantes quando diz que

Da mesma forma como esperamos que as crianças aprendam a ler livros, jornal e poesia em diversos meios, consideramos fun- 
Reflexões sobre os (não) usos das tecnologias digitais na educação física escolar Fábio Souza de Oliveira • Claudio márcio oliveira

\begin{abstract}
damental que o currículo escolar possibilite um trabalho para analisar imagens, notícias, documentários, mensagens publicitárias e para operar com os meios e com as tecnologias da web 2.0 não só para navegar de forma segura, mas para criar, postar e compartilhar conteúdos de maneira responsável (p. 7).
\end{abstract}

Desse modo, compreendemos a Mídia-Educação como o campo de produção de conhecimento que atualmente pode subsidiar o debate a respeito das tecnologias digitais na escola por seu olhar ampliado para esses dispositivos, buscando situar as tecnologias num modelo pedagógico que ultrapasse a dimensão instrumental do seu uso. Cabe à escola direcionar esse potencial de uso para a pesquisa, para organização do conhecimento, resultando em saberes. Finalmente, a escola deve (pre)ocupar-se com o incentivo à autoria com as mídias, posicionamento que inscreve os estudantes na categoria de autores, produtores de conteúdos midiáticos, de conhecimentos refletidos, relacionados à proposta escolar.

\title{
Mídia-Educação Física: reflexões e diálogos possíveis com a Cultura Corporal
}

Vários são os problemas decorrentes da presença das tecnologias na sociedade hoje. Para Sacristán e Pérez Gómez (1998), a televisão (e porque não dizer também a internet), o computador, tablets e celulares, todos oferecem, de modo atrativo, grande acervo de informações sobre os mais variados aspectos da vida, criando, sobretudo nas crianças, concepções ideológicas que elas utilizam para interpretar o mundo. Esse mesmo problema, como tantos outros, reflete também na Educação Física, pelas produções midiáticas relacionadas aos elementos que compõem esse componente curricular. Antes de avançarmos com os olhares sobre a Mídia-Educação na Educação Física escolar, cumpre esclarecer que nos apropriaremos do termo utilizado por Leiro e Ribeiro (2014) quando, ao tratar da Educação Física na perspectiva que 
Reflexões sobre os (não) usos das tecnologias digitais na educação física escolar Fábio Souza de Oliveira • Claudio márcio oliveira

aqui nos propomos, iniciam seu artigo com o título "Pesquisa em Mídia-Educação (física): desafios formativos". Adotamos também o termo por compreendermos o quanto de sentido há em imbricar mídia, educação e Educação Física como áreas equânimes no sentido de formar para as mídias, sendo uma das problemáticas (a nosso ver) da Educação Física atual.

A relação entre a Educação Física e a Mídia-Educação se estabelece a partir do final do século passado e se intensifica a partir de 1997 com a criação do Grupo de Trabalho Temático (GTT) Comunicação e Mídia, no Congresso Brasileiro de Ciências do Esporte (Conbrace), um dos maiores espaços de produção de conhecimento da Educação Física no Brasil (MEZZAROBA; GARCIA; DORENSKI, 2013; SILVA, 2014; SOUSA, BORGES, 2018). Em 2003, nasce, na Universidade Federal de Santa Catarina, o Labomídia, o Grupo de estudos que, desde então, tem discutido e materializado o debate sobre as mídias na sociedade contemporânea (GARCIA et al., 2012). Esses e outros tantos espaços de inserção da MídiaEducação têm permitido o desenvolvimento do conhecimento no campo das mídias nos processos formativos, sobretudo através das pesquisas propostas para a formação inicial e continuada de professores.

O Coletivo de Autores (1992) defende que o objeto da Educação Física escolar é a cultura corporal. Para esses autores, estão no escopo da cultura corporal os jogos, as danças, as lutas, os esportes, as ginásticas. Mais recentemente, a Base Nacional Comum Curricular (BRASIL, 2017), documento que atualmente orienta a elaboração dos currículos escolares no país, caracterizou a Educação Física escolar como o componente curricular que tematiza as práticas corporais, organizadas em seis unidades temáticas: as brincadeiras e jogos, os esportes, as ginásticas, as danças, as lutas e as práticas corporais de aventura. Esses conteúdos, entretanto, não são tratados exclusivamente na escola, pedagogicamente. A partir desses meios (jornal, revista, livro, internet e outros), os estudantes configuram todo um conhecimento a respeito de cada conteúdo com base no discurso midiático que, por sua vez, está impregnado de 
Reflexões sobre os (não) usos das tecnologias digitais na educação física escolar Fábio Souza de Oliveira • Claudio márcio oliveira

interesses e ideologias, sobretudo de ordem político-econômica, que não envolve a totalidade de informações sobre determinado assunto nem pode ser considerado totalmente isento e imparcial (KENSKI, 2012).

A chamada indústria cultural, com a contribuição indispensável das mídias, prescreve atitudes e condutas que nem sempre são percebidas, ou, como menciona Pires (2002, p.130), “[...] sua produção não se dá no nível crítico das consciências [...]". A superação desse estado de dependência, para o autor, só pode ser revertida pela autorreflexão, por um interesse emancipatório do conhecimento. O autor ainda afirma que a construção das ferramentas cognitivas e críticas que possibilitam tal tomada de consciência precisa ser promovida por agentes ou instituições interessadas na libertação dos indivíduos, na emancipação humana. Aqui, lemos: A escola! No que se refere à Educação Física, o autor destaca a artificial produção de necessidades, desejos e interesses direcionados às atividades físicas e aos esportes, além de uma gama de produtos e outros serviços na esteira da sua espetacularização, próprios da indústria cultural. As diferentes mídias têm dado o tom nas representações que os estudantes têm sobre os diversos conteúdos da cultura corporal. As opiniões dos narradores esportivos, massivamente norteadas pelo paradigma do alto rendimento, entrincheiram uma compreensão de esporte que transita pelas vias desse modelo, ignorando outras possibilidades de vivências, experimentações ou discussões sobre esse elemento da cultura corporal. Portanto, não faz tanto sentido para a Educação Física a apresentação desse conhecimento aos alunos no espaço escolar formal quanto reapresentá-lo pedagogicamente, de forma crítica, desvelando os interesses que subjazem os discursos midiáticos.

Por conseguinte, Souza e Mendes (2014) destacam as representações propostas pelas mídias sobre a cultura corporal de movimento, base dos conteúdos da Educação Física. Para esses mesmos autores, os esportes, as danças, as lutas, as ginásticas, todos são apropriados pelas mídias e expostos de forma espetacularizada à população em geral, influência que acaba por empobrecer 
Reflexões sobre os (não) usos das tecnologias digitais na educação física escolar Fábio Souza de Oliveira • Claudio márcio oliveira

a concepção dos estudantes em relação a essa área. Pires (2002, p. 56), ao tratar das formas como as diversas mídias manipulam os elementos do campo da Educação Física, diz que importa compreendê-las criticamente, verificando "[...] as implicações diretas e indiretas da apropriação da cultura de movimento ${ }^{2}$ e esportiva pelo sistema informacional, a fim de perspectivar possibilidades de intervenção da área, voltada a um projeto de construção social da cidadania emancipada".

A Educação Física escolar, assim, assume também o papel de educar para as mídias, formando pessoas capazes não somente de utilizar as diversas mídias de modo operacional, mas de criticar o discurso midiático a respeito desse componente curricular. Para Souza e Mendes (2014), os elementos da cultura corporal estão entre aqueles rotineiramente apropriados e espetacularizados pelas mídias, transformando-os em produtos para a indústria midiática. Segundo esses autores, a linguagem e os meios utilizados pelas mídias, ao concorrer com as formas de comunicação da escola, influenciam mais incisivamente a atenção dos alunos, contribuindo também com maior força para as representações desses estudantes sobre cada um dos elementos da Educação Física escolar. Concordamos com Souza e Mendes (2014) quando afirmam que a forma pela qual as mídias traduzem os elementos da cultura corporal não somente os empobrecem como os distorcem, de tal modo que, ao professor de Educação Física, cumpre zelar pela desmistificação dos conhecimentos propostos pelas mídias.

Certamente, encontraremos no esporte o conteúdo da Educação Física escolar de maior apropriação por parte das mídias, por oferecer o show já pronto e por sua linguagem universal (PIRES, 2002), além de envolver o público com o discurso da fácil mobilidade social (PIRES, 1998), principalmente através do esporte de alto rendimento, no qual também encontramos nas falas e nos silêncios reforços cotidianos à violência, segregação por gênero,

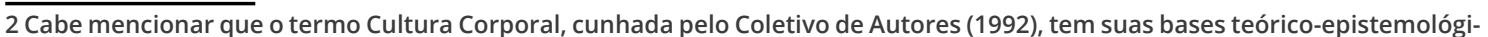
cas alicerçadas pelo materialismo histórico-dialético, enquanto o termo Cultura de Movimento, cunhado por Elenor Kunz (1991, 1994), guarda relações, segundo Bracht (1999), com a obra de Paulo Freire, a fenomenologia de Merleau-Ponty e os autores da Escola de Frankfurt. No entanto, tais perspectivas e termos se alinham na crítica ao reducionismo do corpo humano a mero organismo sem sujeito, assim como na crítica às perspectivas da aptidão física e esportiva como orientadoras do currículo e do fazer pedagógico na Educação Física Escolar. 
Reflexões sobre os (não) usos das tecnologias digitais na educação física escolar Fábio Souza de Oliveira • Claudio márcio oliveira

raça e classe social. Além disso, tais discursos não contemplam o esporte em suas demais manifestações, mais acessíveis e democráticas, como o esporte escolar e o esporte de tempo livre, ou, quando o fazem, direcionam os resultados dessa participação ao esporte de alto rendimento como instância única, necessária e final do fenômeno esportivo.

Assim, as diversas mídias (em alguns casos a própria Educação Física escolar) instrumentalizam o fenômeno esportivo e reduzem-no a uma mercadoria possível de ser usufruída por todos, na condição de espetáculo sem, contudo, permitir o conhecimento de um esporte experimentável do ponto de vista motor, para a maior parte da população. Para a Educação Física escolar, há um agravo: como o professor poderá desconstruir uma representação tão sólida, edificada cotidianamente por "especialistas", pelos "melhores do mundo", estando ele no lugar do professor?

O mesmo raciocínio aplica-se aos demais conteúdos da cultura corporal. As danças, as lutas, os jogos, a capoeira, quando apropriados e transmitidos pelas mídias, assumem papéis que distam daqueles propostos pela Educação Física escolar, de modo que, quando os estudantes finalmente estão diante do professor dessa área, ele (o professor) deve diagnosticar os significados e apropriações já construídos pelos alunos para, a partir daí, reconfigurar esses saberes com vistas à proposta formativa da Educação Física. É nessa perspectiva que concordamos com Sacristán e Pérez Gómez (1998), quando os autores afirmam que a escola é espaço de conhecimento compartilhado que nunca deve renunciar ao processo de construção dialética, impondo suas próprias verdades e representações. Antes, deve valer-se dos esquemas prévios dos alunos, auxiliando-os na reconstrução do conhecimento no sentido de suporte também às suas exigências experienciais.

Desse modo, ao tratarmos das tecnologias digitais móveis na educação e, de modo particular na Educação Física, é imperioso que se discuta a necessária didática que acompanha a entrada dessas tecnologias na escola. Para González e Fensterseifer (2005), a didática, enquanto campo de conhecimento, afirma-se junto com 
Reflexões sobre os (não) usos das tecnologias digitais na educação física escolar Fábio Souza de Oliveira • Claudio márcio oliveira

o advento da escola. Para esses autores, é ela que se ocupa das questões de articulação entre ensino e aprendizagem de forma intencional, visando a organização do processo educacional. Nesse sentido, a adoção de novos conteúdos, métodos, instrumentos ou objetivos, há que se refletir sobre uma nova didática, contextualizada, que dê conta desses dispositivos tecnológicos na educação e, portanto, na Educação Física. A esse respeito, Martín-Barbero (2014, p. 12) afirma que a inserção das tecnologias no espaço escolar, sem um modelo pedagógico e comunicativo, pode, no melhor cenário, "contribuir para modernizar a "decoração" do ensino, e não para a transformação radical das estruturas ou metodologias, tampouco para as práticas de aprendizagem".

Se urgem abordagens críticas na Educação Física escolar que confrontem os discursos midiáticos, por outro lado não se pode perder de vista o potencial produtivo das mídias na escola, particularmente dos dispositivos móveis, tão presentes nas vidas dos estudantes. A partir deles e da leitura crítica feita com base no conteúdo proposto pelas mídias, uma didática da Educação Física escolar pode prever a produção dos próprios conteúdos, alinhando-se à proposta da Mídia-Educação no sentido de fazer apropriação multidimensional das tecnologias digitais.

\section{Considerações finais}

Esta análise argumentativa objetivou refletir sobre os (não) usos das tecnologias digitais na Educação Física escolar. Destacouse que essas tecnologias em si não podem ser consideradas boas ou ruins, não se tratando, portanto, de assumi-las ou refutá-las, num claro posicionamento maniqueísta. Antes, compreendemos a presença das TDIC's nos mais diversos segmentos sociais como fato histórico e, não sendo possível ignorá-las, resta compreendê-las, estabelecendo seu lugar num projeto de educação que as defina enquanto estratégia de ensino ou que, de outro modo, partindo da reflexão sobre princípios políticos, éticos e didáticos, não 
Reflexões sobre os (não) usos das tecnologias digitais na educação física escolar Fábio Souza de Oliveira • Claudio márcio oliveira

as inclua na proposta educacional. Trata-se fundamentalmente de adotar postura docente que se aproxime daquilo que Larossa (2018) chamou de "exercícios de pensamento" e do abandono do binarismo que está no defender ou condenar. Isto posto, um dos desafios que se coloca à educação nacional e à Educação Física, por consequência, refere-se a como lidar com a presença dos dispositivos tecnológicos em meio a jovens em idade escolar.

Desse modo, compreendemos que uma das estratégias privilegiadas no trato com as mídias e/ou com os conteúdos midiáticos é a abordagem mídia-educativa, por avançar na compreensão a respeito das tecnologias digitais na escola, ampliando os seus olhares de uma perspectiva exclusivamente instrumental, estabelecendo possibilidades produtivas e crítico-reflexivas na construção do conhecimento escolarizado.

No que concerne à Educação Física, compreendemos também o quão necessária e urgente é a crítica aos conteúdos midiáticos, relacionados aos elementos da cultura corporal, uma vez que é através das mídias que os jovens em idade escolar obtêm a maior parte das informações que utilizarão para construir as suas representações sobre esses elementos. Disso, acentuamos que é papel da Educação Física escolar criar espaço de reflexão sobre essas aprendizagens espontâneas, tornando os jovens conscientes das concepções distorcidas ou empobrecidas sobre a cultura corporal.

\section{Referências}

ADORNO, T. W. Educação e emancipação. Rio de Janeiro: Paz e Terra, 1995.

ADORNO, T. W. Indústria cultural e sociedade. São Paulo : Paz e Terra, 2002.

AMENDOLA, A.; GIGLI, B.; MONTI. A. M. Adolescenti nella rete. Quando il web diventa uma trappola. L'Asino d'oro edizioni s.r.l., 2018. 
Reflexões sobre os (não) usos das tecnologias digitais na educação física escolar Fábio Souza de Oliveira • Claudio márcio oliveira

BELLONI, M. L. O que é mídia-educação. Campinas/SP: Autores Associados, 2009.

BRACHT, V. A constituição das teorias pedagógicas da educação física. Cadernos Cedes, São Paulo, ano XIX, n 48, agosto/99. Disponível em: http://www.scielo.br/pdf/ccedes/v19n48/ v1948a05.pdf. Acesso em: 05 ago. 2019.

BRASIL. Base Nacional Comum Curricular. Brasília: MEC, 2017. Disponível em: <http://basenacionalcomum.mec.gov.br/images/ BNCC_El_EF_110518_versaofinal_site.pdf>. Acesso em: 04 jul. 2020.

CHARLOT, B. Da relação com o saber às práticas educativas. 1. Ed. São Paulo: Cortez, 2013.

COLETIVO DE AUTORES. Metodologia do ensino de educação física. São Paulo: Cortez, 1992.

FANTIN, M. Mídia-Educação: conceitos, experiências, diálogos Brasil-itália. Florianópolis: Cidade Futura, 2006. 264p.

FANTIN, M. O lugar da experiência, da cultura e da aprendizagem multimídia na formação de professores. Rev. Educação, Santa Maria, v. 37, n. 2, p. 291-306, maio 2012. Disponível em: https:// periodicos.ufsm.br/reveducacao/article/view/4864/3241. Acesso em: 05 ago. 2019.

FANTIN, M.; RIVOLTELLA, P. C. (orgs.). Cultura digital e escola: Pesquisa e formação de professores. Campinas, SP: Papirus, 2012 GARCIA, L. C. P. et al. A formação profissional em educação física e a temática das tecnologias da informação e comunicação e mídia esportiva: contribuições do Labomídia - UFS. In: II Congresso internacional de formação profissional em educação física. vi seminário de estudos e pesquisas em formação profissional no campo da educação física. Florianópolis, 2012. Anais [...]. Florianópolis: FEFD/UFG, 2012. p. 640-650. Disponível em: <https://ri.ufs.br/ bitstream/riufs/11433/2/FormacaoProfissionalEducacaoFisicaTIC. pdf>. Acesso em: 09 ago. 2019. 
Reflexões sobre os (não) usos das tecnologias digitais na educação física escolar Fábio Souza de Oliveira • Claudio márcio oliveira

GONZÁLEZ, J.; FENSTERSEIFER, P.E. Dicionário crítico de educação física. ljuí: Ed. Unijuí, 2005. 424p.

KENSKI, V.M. Educação e tecnologias: o novo ritmo da informação. $8^{a}$ ed. Campinas, SP: Papirus, 2012.

KUNZ, E. Educação Física: Ensino e Mudanças. ljuí: Unijuí, 1991

KUNZ, E. Transformação didático-pedagógica do esporte. ljuí: Unijuí, 1994

LAROSSA, J. Elogio da Escola. 1. ed.;1. reimpr. - Belo Horizonte: Autêntica Editora, 2018. - (Coleção Educação; Experiência e Sentido)

LEIRO, A.C.R.; RIBEIRO, S.D.D. Pesquisa em Mídia-Educação (física): desafios formativos. Cadernos de formação RBCE, Santa Catarina, v.5, n2, p. 14-25, set. 2014. Disponível em: http://revista. cbce.org.br/index.php/cadernos/article/view/2062/1017. Acesso em: 10 jul. 2020.

MARTíN-BARBERO, J. A comunicação na educação. São Paulo: Contexto, 2014

MCLUHAN, M. Os meios de comunicação como extensões do homem. São Paulo: Cultrix, 1964

MEZZAROBA, C.; GARCIA, L.C.P.; DORENSKI, S. Mídia-Educação e suas interfaces com a Educação Física: Algumas experiências do LaboMidia/UFS. Revista Praxia, Goiás, v. 1, n. 2, 2013. Disponível em: https://www.revista.ueg.br/index.php/praxia/article/ view/1418/944. Acesso em: 10 jul. 2020.

MILLS, C. W. A imaginação sociológica. Rio de Janeiro: Zahar, 1972.

PIRES, G.L. Breve introdução ao estudo dos processos de apropriação social do fenômeno esporte. Rev. da educação física, Maringá,1998. Disponível em: http://periodicos.uem.br/ojs/index. php/RevEducFis/article/view/3824/2636. Acesso em: 10 jul. 2020.

PIRES, G.L. Educação física e o discurso midiático: abordagem crítico-emancipatória. ljuí: Ed. Unijuí, 2002. 336p. 
Reflexões sobre os (não) usos das tecnologias digitais na educação física escolar Fábio Souza de Oliveira • Claudio márcio oliveira

PUCCI, B. et al. Atualidade da teoria crítica na era global. (org).1. ed. São Paulo: Nankim, 2016.

SACRISTÁN, J.G.; PÉREZ GÓMEZ, A. I. Compreender e

Transformar o Ensino. Porto Alegre: Artmed, 1998.

SILVA, W.A. Tecnologia, educação física e o ensino do esporte. 1.ed. Curitiba: Appris, 2014. 157p.

SOUSA, G.R.; BORGES, E.M. Perspectivas histórico-sociais no campo da Mídia-Educação: contribuições para a formação em Educação Física. Revista Motrivivência, Santa Catarina, v. 30, n. 55, p. 194-207, set. 2018. Disponível em: https://periodicos. ufsc.br/index.php/motrivivencia/article/view/2175-8042.2018v30n55p194/37573. Acesso em: 10 jul. 2020.

SOUZA, G.R.; MENDES, D.S. Mídias na formação em educação física: análise de uma disciplina optativa. Revista Motrivivência, Santa Catarina, v. 26, n. 43, p. 300-315, dezembro/2014.

Disponível em: https://periodicos.ufsc.br/index.php/motrivivencia/article/view/2175-8042.2014v26n43p300/28126. Acesso em: 10 jul. 2020.

TÜRCKE, C. Sociedade excitada: filosofia da sensação. Campinas, SP: Editora da Unicamp, 2010.

\title{
Publisher
}

\begin{abstract}
Universidade Federal de Goiás. Faculdade de Educação Física e Dança. Publicação no Portal de Periódicos UFG. As ideias expressadas neste artigo são de responsabilidade de seus autores, não representando, necessariamente, a opinião dos editores ou da universidade.
\end{abstract}

